\title{
DESIGN AND VERIFICATION OF ENGINE POWER CALCULATION MODEL USING THE DATA OF A DIGITAL BUS BUILT INTO AN AGRICULTURAL TRACTOR
}

\author{
J. Čupera, P. Sedlák
}

Received: March 16, 2011

\begin{abstract}
ČUPERA, J., SEDLÁK, P.: Design and verification of engine power calculation model using the data of a digital bus built into an agricultural tractor. Acta univ. agric. et silvic. Mendel. Brun., 2011, LIX, No. 6, pp. 111-120

Engine power is a fundamental parameter for determining the utilization of an agricultural tractor. A wrong combination of a tractor and agricultural machinery leads to non-efficient loading of the engine, which causes not only a waste of energy stored in the fuel but also increased financial cost of production. The presented paper focuses on the possibility to calculate engine power from the data, which are available on the digital bus - CAN-BUS. Choosing the appropriate parameters together with the proposed model can help represent the instantaneous power needs. The messages, which provide the basic information about the load, are as follows: engine load, instantaneous torque, instantaneous fuel consumption, engine speed and a set of correction channels. These channels bring the cluster of temperatures and pressures of engine fluids, mainly of the fuel and engine lubricating oil. Without prior determination of the regression function, the data, especially in low load, are very different from the actual torque generated by the engine and measured by a dynamometer. The model represents a function of surface features with a very high index of determination. The model was verified by measuring the power of the engine on a dynamometer. Validation of the model in practice was carried out in the field. The tractor was connected with combined cultivator. The experiment results show a very high statistical match of the results obtained in the laboratory and in field measurements.
\end{abstract}

agricultural tractor, CAN-BUS, engine power, engine torque

The efficiency of the work performed by a tractor engine is significantly influenced by the energy needs of corresponding agricultural machinery. Aggregation of machinery is a difficult task, because the power demands are affected by many factors - soil conditions, environmental conditions, etc. Earlier tractor sets had to provide sufficient power reserve. The electronics of current tractors allow short-term engine power boost. To assemble a suitable working set it is necessary to understand the needs of the tractor engine. The control systems for each tractor component are now equipped with computer networks based on digital buses. One of the most important ones is the CAN-BUS. Its description is given by Bosch (2006) and further applications have been written by Auernhammer and Speckmann (2006). The frames of the CANBUS contain the necessary information about engine load, but my experiences with the use of these data always makes me question the accuracy of indirect methods. The published output of the experimental work using these data is focused on the mobility parameters of vehicles, Suvinen and Saarilahti (2006). The experimental work described in this article brings results regarding determined precision of CAN data. 


\section{MATERIAL AND METHODS}

Measurements were done in the Vehicle laboratories of the Department of Engineering and Automobile Transport at Mendel University in Brno. The second part of testing was carried out in the field. The aim was to verify the possibility of performing measurements using the messages coming from the CAN-BUS of a tractor. The object of our work was to determine the engine power on the basis of data readings from the CAN-BUS during the tractor's operation. Given our previous experience with uncertainty of obtained values, it was necessary to select the appropriate channels and determine their accuracy. The obtained data were used to design an engine power determination model. For this purpose it was necessary to compare the values obtained from internal sensors in the tractor with the ones from externally mounted sensors. In the second stage of measurements, field tests were carried out and verified. The Claas Axion 850 Cebis was used as a sample.

The full engine characteristics were measured to determine the accuracy of the CAN-BUS values. These measurements were carried out in a way so that the engine was loaded within the range of full engine characteristic according to selected points. The main purpose was to achieve uniform distribution of the measured points. The full engine characteristic is thus not determined by direct measurements, as rated characteristics, but it is a construction of a surface composed of curves measured at various fuel supply and engine load levels. General requirements according to ISO 789-1 were respected. A chart of full engine characteristic was constructed from partial potential characteristics (11 curves) and from the envelope curve, which represented rated torque characteristic. To calculate the instantaneous engine power, the instantaneous torque obtained as a percentage value from the CAN-BUS appears to be the most appropriate of the measurements made. Therefore, a full torque characteristic consisting of instantaneous torque curves was made before field testing. The curves of partial load were fitted by polynomial interpolation. Both torque values - measured by a dynamometer and read from the CAN-BUS, were sampled simultaneously and processed by the method of least squares as well. The order of the polynomial interpolation used was set so as to obtain the highest value of the coefficient of determination. This way a true curve of fitted data is guaranteed. The engine torque was calculated on the basis of actual value of torque transmitted via the CANBUS. Similarly, an equation of linear dependence of torque and engine speed was computed for every curve of partial load. By substituting the previously computed value of torque in the equation of the line of speed characteristic the value of engine speed can be determined where the instantaneous torque detected by CAN was achieved. By fitting the calculated values into all curves in the speed characteristics, we will obtain isolines describing other instantaneous torque values. The same procedure was used for all isolines of torque. Testing was carried out in the Vehicle Laboratory at Mendel University. Engine parameters were measured under load generated by an eddy current dynamometer. The torque was transferred via PTO (see Fig. 1). Torque and speed of the output shaft were measured together with the following parameters: fuel mass consumption, intake air temperature, inlet air pressure, compressed air temperature at the turbocharger outlet, air temperature after intercooler, engine oil temperature, engine coolant temperature, exhaust gas temperature etc. The CANBUS data and values of the test bench were sampled simultaneously. The CAN-BUS of the tested tractor was fully compatible according to the requirements of SAE recommendation J1939 in extended Arbitration ID $(29$ bit). The communication speed usually used was $250 \mathrm{kbps}$. The analysis of frames rendered the following relevant channels: instantaneous torque, engine speed (revs), engine load, intake air temperature, fuel temperature, fuel rate etc. Ambient conditions (barometric pressure, humidity and air temperature) were monitored and stored in the file together with all channels. The testing procedure was performed according to ISO 789-1. Sample rate was set to default, which meant a time period of $55 \mathrm{~ms}$.

I: Description of the tractor Claas Axion 850 Cebis

\begin{tabular}{|c|c|c|c|}
\hline \multirow{9}{*}{ Engine } & \multirow{2}{*}{$\begin{array}{l}\text { Model } \\
\text { Rated engine power (ECE-R24) }\end{array}$} & \multicolumn{2}{|c|}{ 6068HRT83 DPS } \\
\hline & & 169 & $\mathrm{~kW}$ at $2000 \mathrm{rpm}$ \\
\hline & Maximal engine power (ECE-R24) & 193 & $\mathrm{~kW}$ at $2000 \mathrm{rpm}$ \\
\hline & Rated torque & 1020 & Nm at $1500 \mathrm{rpm}$ \\
\hline & Number of cylinders & 6 & \\
\hline & Engine displacement & 6788 & $\mathrm{ccm}$ \\
\hline & Engine cooling & \multicolumn{2}{|l|}{ Water } \\
\hline & Charging & \multicolumn{2}{|c|}{ Turbocharged with air pressure regulation } \\
\hline & Injection & \multicolumn{2}{|c|}{ Common Rail } \\
\hline \multirow{2}{*}{ Gearbox } & Model & \multicolumn{2}{|c|}{ HexaShift, torque multiplier (6 deg.) } \\
\hline & No. of gears & \multicolumn{2}{|c|}{24 front/24 rear } \\
\hline
\end{tabular}




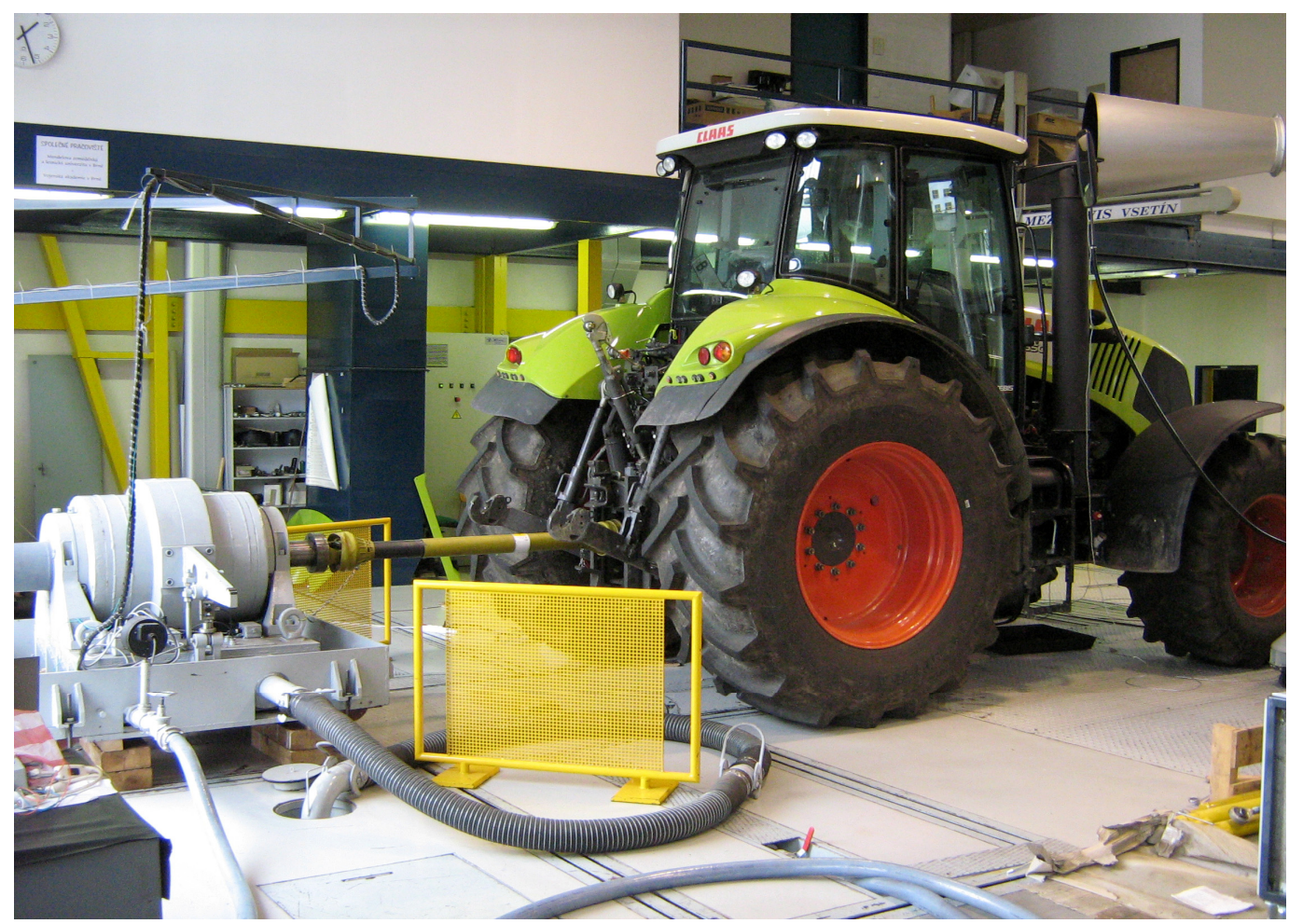

1: Tractor Claas Axion 850 Cebis at the test bench with connected PTO

The torque value was measured by an eddy dynamometer connected to PTO via a shaft. Regulation and data acquisition was provided by a regulation system of the test bench. The measured data were saved into an Excel file. Specifications of the dynamometer are given in Tab. II.

II: Description of the eddy dynamometer used for the measurements

\begin{tabular}{|c|c|c|c|c|}
\hline \multicolumn{2}{|c|}{ Type of dynamometer } & \multicolumn{3}{|c|}{ V 500} \\
\hline Input speed & {$\left[\mathrm{min}^{-1}\right]$} & 150 & 1500 & 3000 \\
\hline $\begin{array}{l}\text { Maximal } \\
\text { measured power }\end{array}$ & {$[\mathrm{kW}]$} & 4 & 500 & 500 \\
\hline $\begin{array}{l}\text { Maximal input } \\
\text { torque }\end{array}$ & {$[\mathrm{Nm}]$} & 254 & 3184 & 1592 \\
\hline Cooling system & & \multicolumn{3}{|c|}{ water-cooled } \\
\hline Load & & \multicolumn{3}{|c|}{ Steady-state } \\
\hline
\end{tabular}

Measurement of fuel consumption was carried out using two Coriolis mass flowmeters Sitrans FC MASS 6000 MASSFLO in differential connection to prevent possible effect on the fuel system of the tractor. Other systems of fuel metering could add a very high pressure loss. The values of temperature were measured with $\mathrm{K}$ - thermocouples; the values of pressure were measured using piesoresistive sensors. Data obtained from the test bench instrumentation were extended by a data matrix of the CAN network. The solution of CAN listening can be ensured by many software applications but our target was to collect data within the same time base. Therefore, we created our own application in the LabVIEW development studio from National Instruments. The second part of research was focused on verification of obtained data in the field. The tractor worked with combined cultivator.

The tests were conducted on a flat field with sandy-loamy soil near the village of Bantice. The surface of the field after the harvest of winter wheat had been treated by discs harrows to a depth of $8 \mathrm{~cm}$. Testing sections were delimited on a flat stretch as the measuring track. The tests consisted of two sets of gear shifting. The first one shall be refered to as $\mathrm{B}$ and the other one as $\mathrm{C}$. The reason for this decision lies in the possibility of engine power boost occurring if the $\mathrm{C}$ group is chosen. In the field tests also the data from internal and external sensors installed in the tractor systems were measured for the purpose of the tests. The data coming from the internal sensors were obtained by reading the CAN network. The main sample rate was set to 20 samples per second. The external device for determining the ground speed was based on TGSS RDS radar sensors. Because of possible inaccuracy of the radar measurements caused by surface roughness, a GPS module was mounted onto the tractor roof. Theoretical velocity was measured with the support of an incremental sensor. A trigger signal indicating the start and the end of measurement was taken from a reflective red light sensor. The signals from external sensors were brought to the measuring unit and amplifier Spider8. The data were processed by proprietary software and saved to hard disc of a measuring laptop (see Fig. 2). For that purpose we needed to write our own application in the 


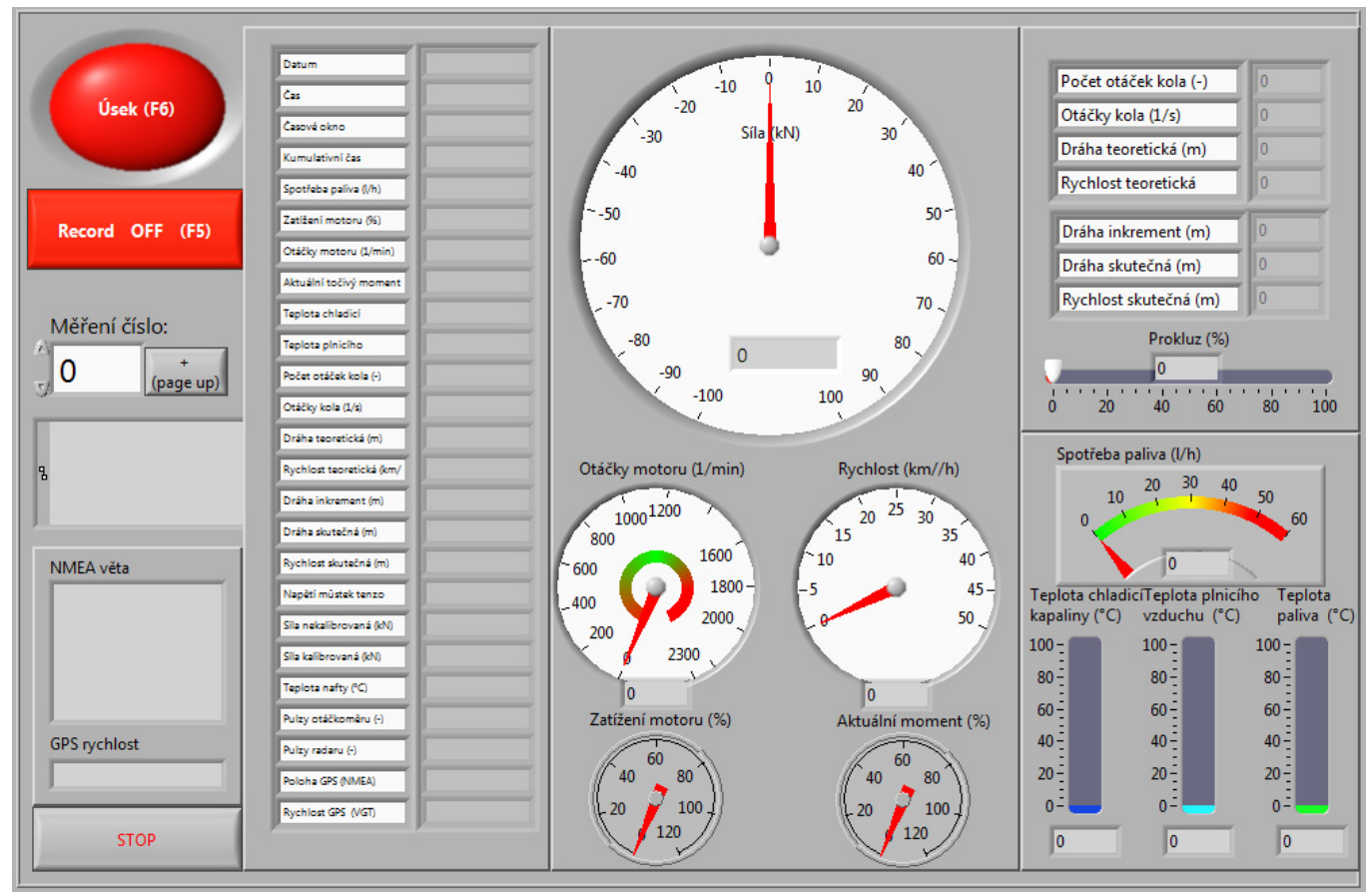

2: Front panel of the developed application

LabVIEW from National Instruments. The internal architecture consists of four loops; one for each of the three devices, the fourth loop is used to save the data to a file. Data synchronization is ensured by resetting the loops with a real delay difference of $10 \mathrm{~ms}$. Sampling of the data was adjusted to the maximum required sampling, meaning that the data were then repeated in a loop, unless a change was detected. The routine of Spider8 includes not only value readings but also complete configuration of the amplifier, especially the port communication settings. In this loop, there are also calibration constants and other transformation functions. A CAN-BUS subroutine collects the data from the bus, or, as the case may be, it performs filtering of the data on the hardware physical layer and interprets them in a decimal form. The GPS loop decodes standard NMEA sentences in ASCII format. The data from the previous routines are sent into the saving loop via global and shared variables. If the record button is pushed, the computer will store the data in an ASCII data file with a predefined sampling (20 Hz sample rate found to be optimum).

The measurement of engine parameters via PTO, and measurement of drawbar performance was carried out in accordance with the OECD methodology. Evaluation of the measured data from field tests was performed according to standard procedures described in the literature.

One of the objectives of the field tests was also to carry out verification of the engine power calculation and to determine the effect of power boost on the energy parameters of the tractor set with the working machine. The measurements were made using a Claas Axion 850 tractor connected with a combined cultivator Cebis Väderstat 350 Cultus (see Fig. 3). Technical specifications of the cultivator are given in Tab. III) Testing sections of the track were $250 \mathrm{~m}$ long. One measurement consisted of two runs with a full working width. It means that there was no overlap of the areas covered by each run. At the end of the testing section, the working tractor turned around and continued back to the beginning of the track. The set of the tractor and cultivator was subjected to measurements at different working depth settings. The cultivator was attached to the tractor using a bar located at the bottom of connecting rods. The frame of the cultivator was kept in a plane parallel to the ground when operating. Two sets of gear shifting (B and C) were tested and compared in terms of the value of engine power. Fuel supply was always set to maximum using the manual governor. During the tests, the tractor axle differential lock was turned on. The tractor was equipped with a ballast of $1200 \mathrm{~kg}$ attached to the front three-point linkage. The calculation of engine power and indicators of performance are based on the following parameters: engine speed, instantaneous torque, fuel consumption, ground speed, theoretical speed, time for each operation and engine load.

III: Technical description of the combined cultivator

\begin{tabular}{lll}
\hline \multicolumn{1}{c}{ Type: } & Väderstat Cultus CS 350 \\
\cline { 1 - 2 } Serial number: & CS 10759 \\
Construction width & $3,5 \mathrm{~m}$ \\
Weight & $2600 \mathrm{~kg}$ \\
Year of manufacturing: & 2009 \\
\hline
\end{tabular}




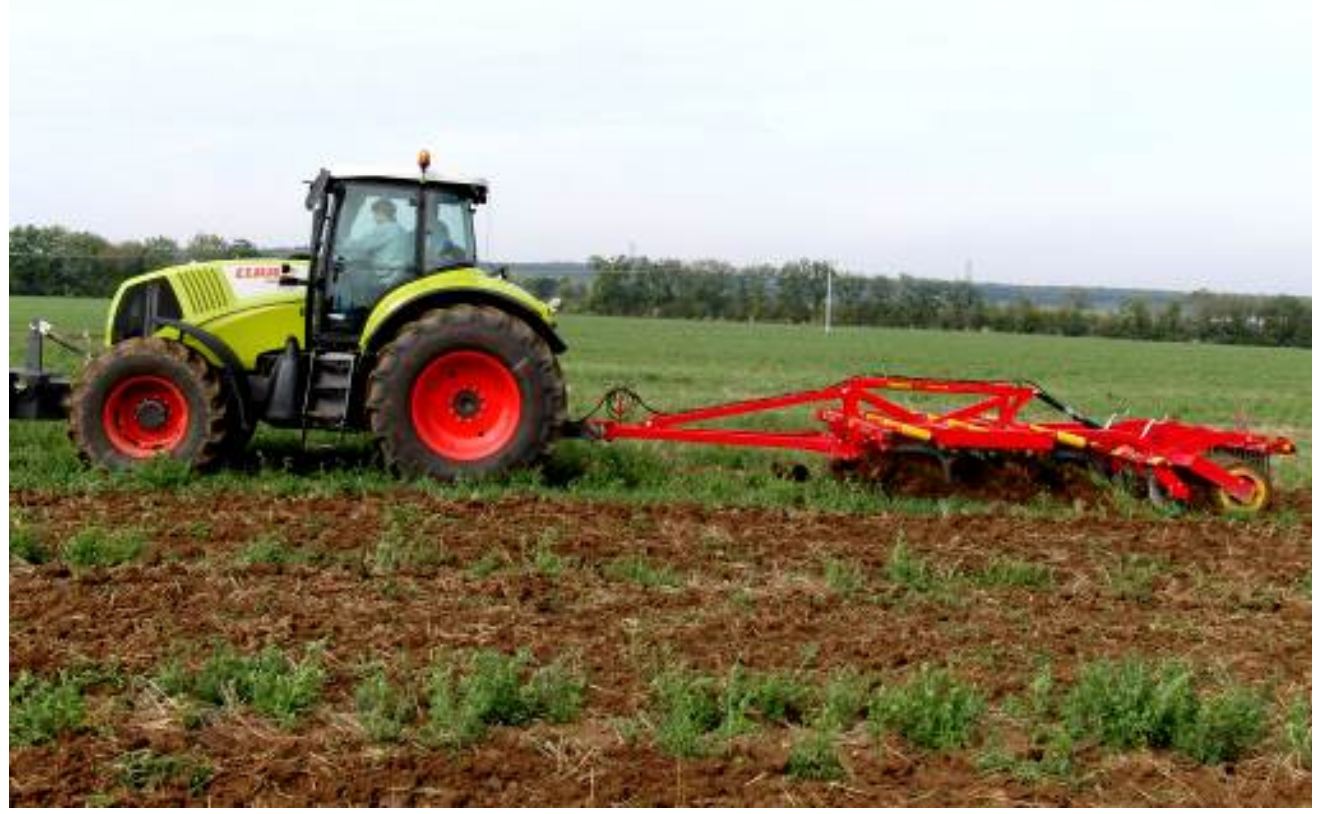

3: The working set of Claas 850 Axion tractor and Väderstat Cultus CS 350 combined cultivator

The combined cultivator is composed of three working sections. The first section is a cultivator with three rows of tines. The second section consists of greaseless leveling discs with rubber suspension. The last section consists of a rubber roller.

\section{RESULTS AND DISCUSSION}

To assess the possibility of using the CAN-BUS data on instantaneous torque, it was necessary to compare these data with the measurements results in the laboratory. Similar measurements were made by authors Murthy, Ramakrishna (2009), who monitored the operational status of the tractor during 100 hours. They too used the CAN-BUS for this purpose. Their results brought interesting data such as the engine speed where the histogram shows that the tractor engine operates at speeds above $2000 \mathrm{rpm}$ most frequently. The message of instantaneous torque is presented as a percentage meaning that conversion into real value must be carried out with the aid of full engine characteristic (see Fig. 4). The outside curves represent engine

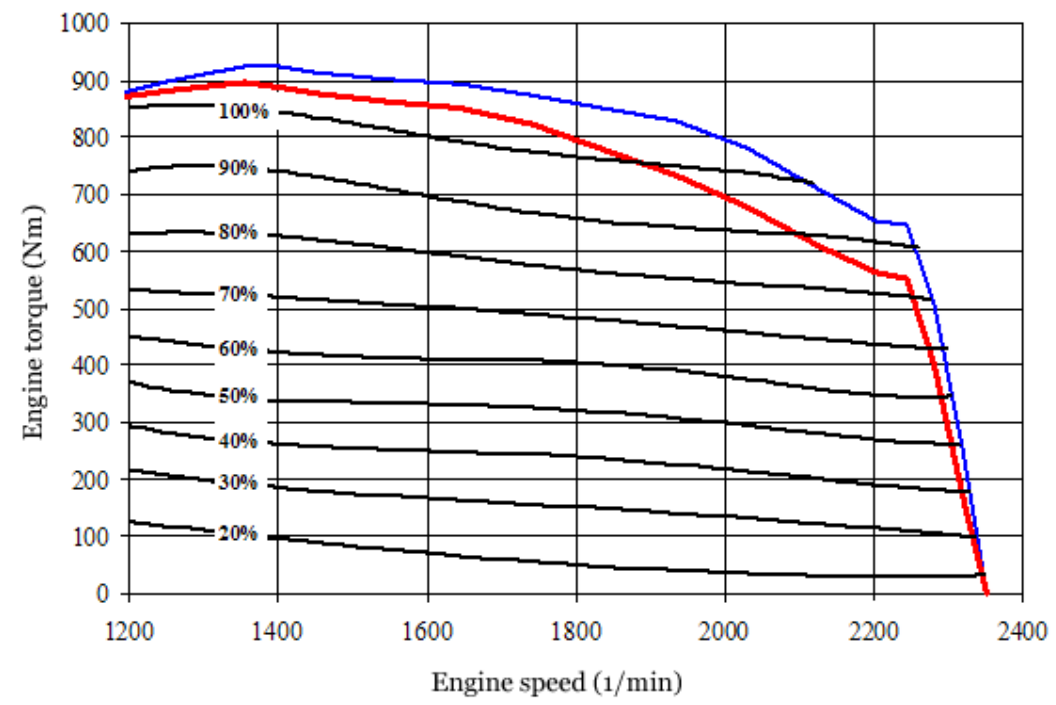

4: Torque curves of Claas 850 Axion tractor with isolines of CAN-BUS values of torque 
power with and without power boost mode. Engine power boost was activated by electronics in the case of laboratory measurement. The isolines labeled by percentage values show instantaneous torque taken from the CAN-BUS. The chart featuring rated torque (see Figure 4) clearly shows that without power boost the torque increase is about $65.9 \%$ while the engine speed decreases by about 39.5\%. By turning on the power boost the torque increase dropped to about $46.6 \%$ with $39.6 \%$ drop in engine speed.

The increase in engine power, which can be seen in graph on the Fig. 4, is achieved by increasing the supply of fuel, which is evident from the course of injection volume. Activation conditions for engine boost are stored inside the electronic control unit.

The full engine characteristic shows isolines of instantaneous torque taken from the CAN-BUS. The chart shows that the data from the CAN network do not correspond with the values measured via PTO. The largest deviations were measured at a low percentage of the current torque. For example, in case of the instantaneous moment of $20 \%$ at a speed of $1400 \mathrm{~min}^{-1}$, it is evident from the graph that the instantaneous torque should correspond to the actual measured torque of $170 \mathrm{Nm}$. In fact, however, it is only $100 \mathrm{Nm}$, which is a 41\% deviation from the desired value. At the speed of about 1800 $\mathrm{min}^{-1}$ and with the same instantaneous moment this makes a $65 \%$ deviation. The above clearly shows that the rate of data error from the CAN network is growing with increasing engine speed. The error does decrease with higher loads but the tractor was measured at full load with values greater than $100 \%$ (up to 111\%). From the above it is clear that a simple comparison of the measured torque with maximum torque values stated by the CAN would be subject to considerable error. For the improvement of accuracy of CAN readings it is therefore necessary to measure the torque by a dynamometer.

The determination of the actual power value requires calculation of a surface equation, where the curves of engine power are drawn in dependence on the torque and engine speed. Regression analysis was calculated from the measured values of the regression equation using the area, which can provide actual power value. Statistical description is given in Tab. IV and Tab. V. The general equation of the calculated surface has this form:

$P=a+b \times n+c \times n^{2}+d \times A M t+e \times A M t^{2}+f \times n \times A M t$,

$[\mathrm{kW}]$

where:

P.......engine power $(\mathrm{kW})$,

$\mathrm{N}$.......engine speed $\left(\mathrm{min}^{-1}\right)$,

AM ..instantaneous torque taken from CAN (\%),

a...f..regression equation coefficients.

From the above analysis of measurement results in the laboratory, it is clear that the calculated regression function represent the measured values very well. It is thus possible to use it to determine the values of instantaneous power using the readings from the CAN-BUS when in operation. The courses of curves for constant engine power values might be found from the regression surface of dependence on the engine speed and - the instantaneous torque. The construction of the chart of isolines is as follows. We keep the planes parallel to the xy plane (n-MTA) at the corresponding heights (selected power values), these intersect the regression surface at intersections whose projections in the xy plane constitute the isolines for constant power.

If the general notation of the calculated regression surface is (see equation 1 )

$z=a+b \times x+c \times x^{2}+d \times y+e \times y^{2}+f \times x \times y$.

The equation of a plane parallel to the xy plane is (see Fig. 5):

$g \times z+h=0$.

A common solution to both equations (2) and ( 3 ) is obtained in the form of equation of the intersection representing a curve of constant power, where the chosen power is $\mathrm{P}=\mathrm{h} / \mathrm{g}$. Solving these equations for y leads to a quadratic equation in the form of:

IV: Analysis of variance

\begin{tabular}{|c|c|c|c|c|c|}
\hline & Degree of freedom & Sum of squares & Mean square & F statistic & $\mathbf{F}>\mathbf{P}$ \\
\hline Error & 306 & 1598.289 & 5.223167 & & \\
\hline Total & 311 & 535798 & & & \\
\hline
\end{tabular}

V: Calculation of the coefficient of regression function and its significance

\begin{tabular}{lcccc}
\hline & Coefficient & Standard deviation & t stat & P value \\
\hline Intercept & $-3.23 \mathrm{E}+01$ & 4.564381 & -7.07705 & $1.01 \mathrm{E}-11$ \\
$\mathrm{n}$ & $5.49 \mathrm{E}-02$ & 0.004387 & 12.51722 & $2.62 \mathrm{E}-29$ \\
$\mathrm{n} 2$ & $-2.35 \mathrm{E}-05$ & $1.14 \mathrm{E}-06$ & -20.5674 & $1.24 \mathrm{E}-59$ \\
AMt & $-2.70 \mathrm{E}-01$ & 0.04813 & -5.60405 & $4.67 \mathrm{E}-08$ \\
AMt2 & $3.06 \mathrm{E}-03$ & 0.000246 & 12.44877 & $4.63 \mathrm{E}-29$ \\
n*AMt & 8.45E-04 & $1.56 \mathrm{E}-05$ & 54.13121 & $9.1 \mathrm{E}-159$ \\
\hline
\end{tabular}




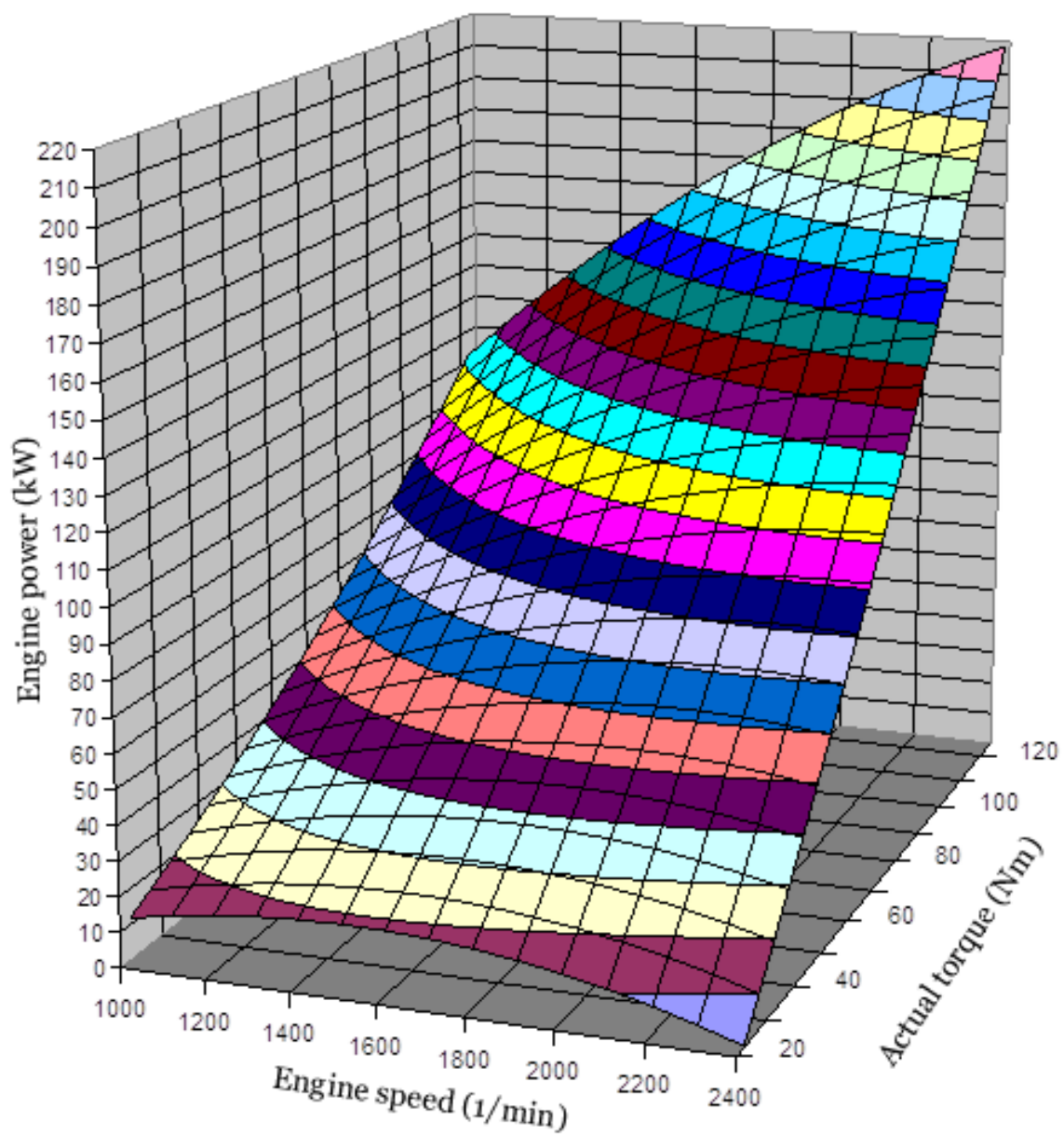

口210-220

口200-210

口190-200

ㅁ180-190

口170-180

ㅁ160-170

- 150-160

0140-150

- 130-140

-120-130

ㅁ110-120

ㅁ100-110

- $90-100$

-80-90

प70-80

$\square 60-70$

$\square 50-60$

- 40-50

$\square 30-40$

口20-30

口10-20

마-10

5: Claas 850 tractor engine power curve in dependence on the torque taken from CAN-BUS

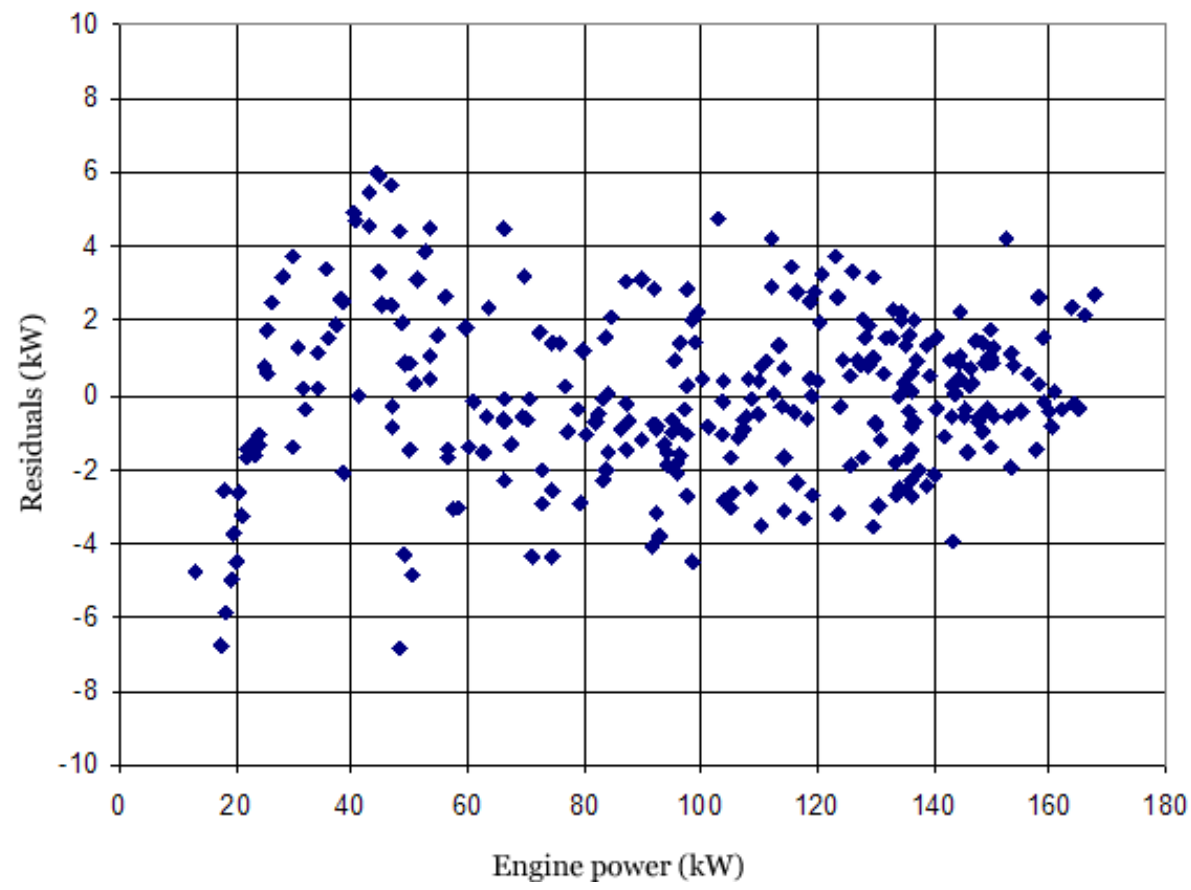

6: Residuals of the engine power deviations from the regression surface 

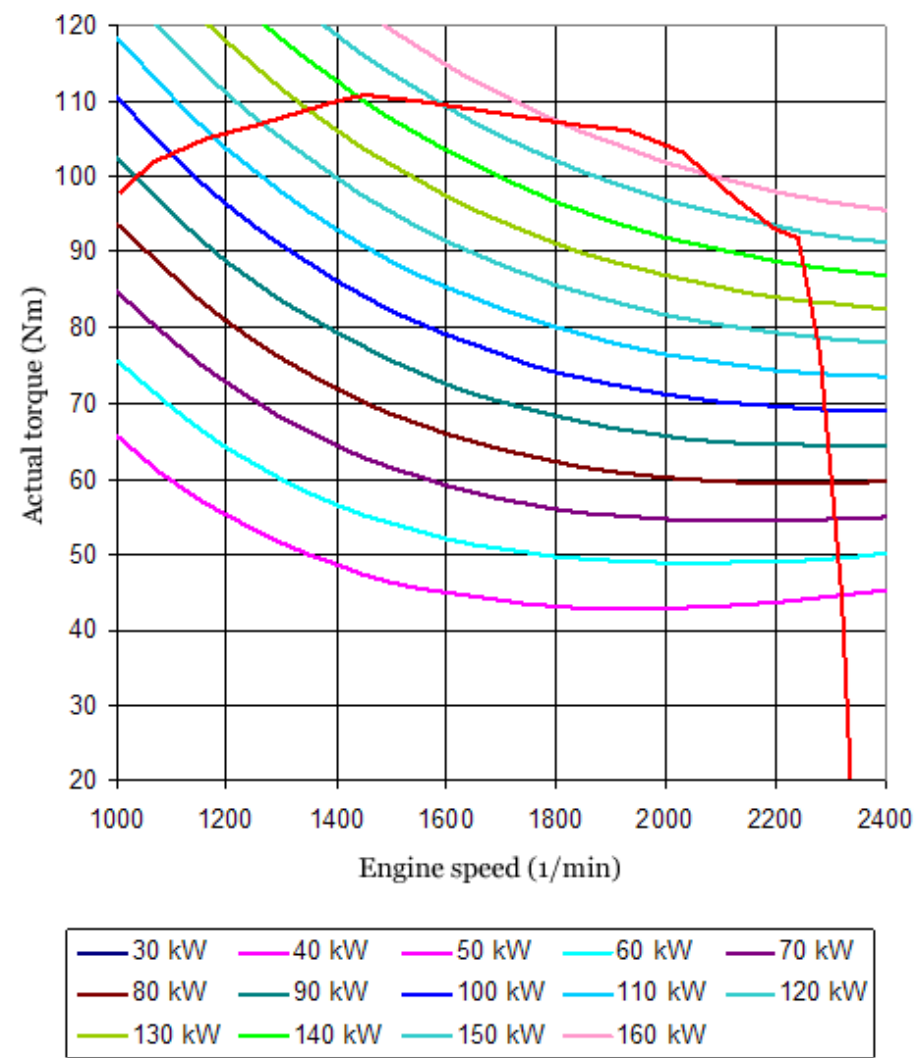

7: A chart of isolines representing engine power of the tractor Claas 850 Axion

$$
e \times y^{2}+(d+f \times x) \times y+\left(a-\frac{h}{g}+b \times x+c \times x^{2}\right)=0 .
$$

The real roots are positive, meaning that the positive values are also the values of instantaneous torque. Thus calculated curves for constant power are plotted in graphs in Fig. 7 and Figure 8. In this characteristic, the rated torque with a full supply of fuel is shown for clarity. The graphs show that the curves of constant power differ from the hyperboles in the standard full characteristic of n-Mt coordinates. In this coordinate system, the power curves are characterized by a known formula:

$M_{t}=\frac{\mathrm{P}}{2 \times \pi \times n}$.

The deviations from the hyperbolas shown in Fig. 7 and Fig. 8 are caused by the fact that the correlation between the actual measured torque (Mt) and the instantaneous torque taken from the CAN-Bus (MTA) is not linear and it changes with growing engine speed. The largest deviations from the hyperbolas are especially clearly visible at lower power levels.

\section{CONCLUSION}

The aim of the laboratory and field measurements was to obtain a verified model of engine power determination based on data taken from the CANBUS. Real operation data of a tractor set were used for the comparison with calculated equations. The tractor was tested in a laboratory before field measurements were carried out. Measuring in the laboratory was focused on matching the values obtained directly from a test bench and indirectly from the CAN-BUS. These results were plotted into a full engine characteristic. Analyses of the results pointed to the fact that the use of pure data taken from CAN-BUS could not be used for further processing without regression. Therefore, we performed laboratory measurements with the intent to design a model for the determination of engine power. The model allows us to use the data obtained from the network to determine the basic tractor engine parameter, which is the engine power. The advantage of using the proposed model is that it is possible to monitor the engine's operating parameters using the data from the tractor's internal sensors with minimal cost. Mostly, all external sensors cannot be mounted simultaneously. The article is an example of verification of the proposed model in practice when operating Claas Axion 850 tractor with a cultivator. The proposed model can be used in practice to determine the energy performance of different machines working in a set with a tractor. 


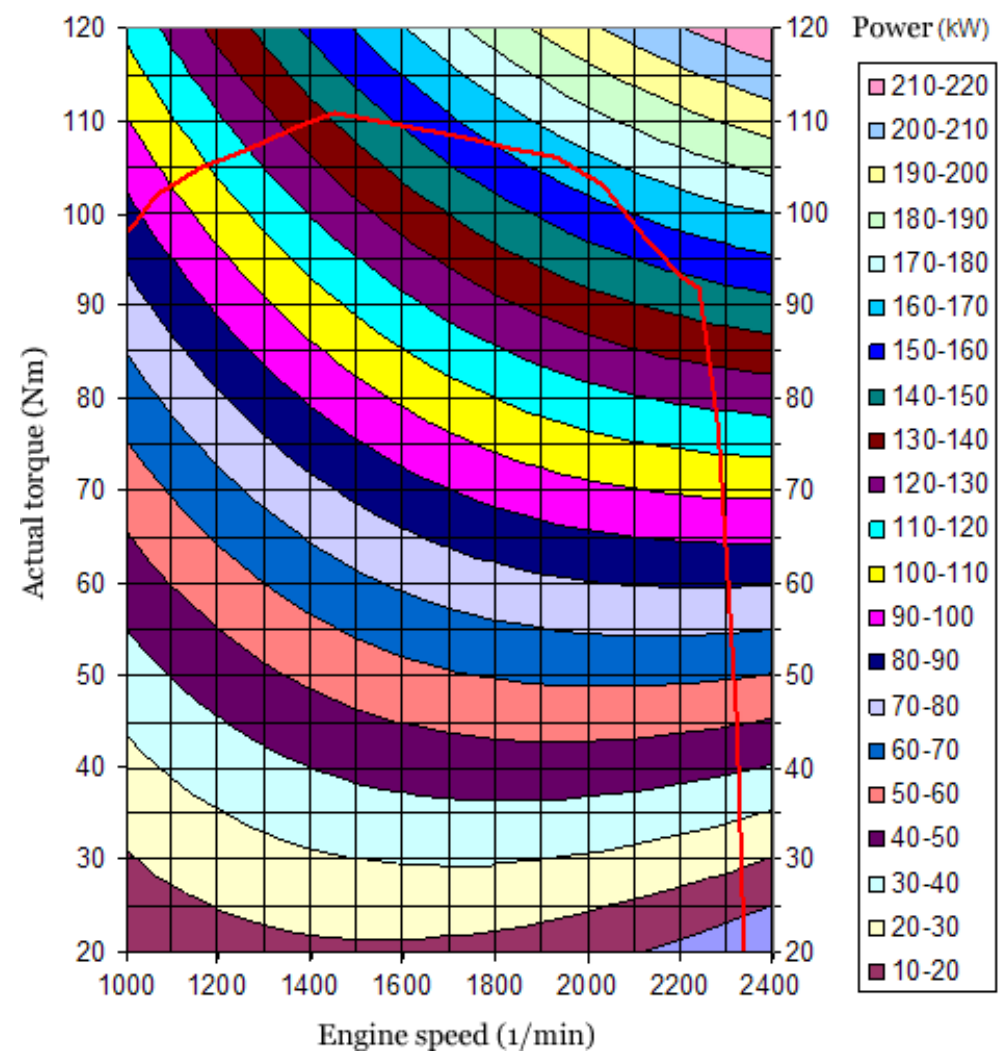

8: A chart of constant engine power for Claas 850 Axion engine in n-Amt coordinates

\section{SUMMARY}

The work is focused on the possibility of using messages of CAN-BUS for attaching agricultural machinery. The basic parameter is the amount of instantaneous torque and engine speed. The channel of generated instantaneous torque is described in the specification SAE J1939. The goal of the experimental work was to design a mathematical model, which will be able to use energy efficiency for further determination and needs in agricultural production. Validation of the model was carried out in field conditions with a Claas Axion 850 Cebis tractor attached to a combined cultivator Väderstat Cultus 350. Laboratory measurements were carried out before field testing. A full characteristic of the engine was measured on an eddy current dynamometer. The selected channels of CAN-BUS were sampled simultaneously with the values obtained from a test bench. By plotting the results of measurements into a graph, it was discovered that the variation of direct and indirect methods is very significant. The instantaneous torque presented by CAN-BUS at the engine speed of $1400 \mathrm{~min}^{-1}$ was about $20 \%$, which would imply a value of $170 \mathrm{Nm}$. However, the actual measured value of the engine torque was only $100 \mathrm{Nm}$. The difference is thus 41\%. Regression analysis was calculated from the measured values of the regression equation describing the surface of engine power. The precision of the dependence is shown by the coefficient of determination, which rises to 0.99851 , thus $99.85 \%$ of the variance is explained by the calculated regression function. This means that higher engine power brings higher calculation accuracy. From the analysis of residues it can be seen that for higher loads the maximum deviation from the calculated area is about $\pm 2.5 \%$ of maximum power. The model is thus sufficiently accurate for possible further analysis, which would be based on these data.

\section{Acknowledgement}

The paper was prepared with support of Internal Grant Agency No. TP1/2011 - Monitoring of performance parameters of tractor's engine and with support of the Research plan No. MSM6215648905 "Biological and technological aspects of sustainability of controlled ecosystems and their adaptability to climate change", which is financed by the Ministry of Education, Youth and Sports of the Czech Republic. 


\section{REFERENCES}

AUERNHAMMER, H., SPECKMANN, H., 2006: Dedicated Communication Systems and Standards for Agricultural Applications. Chapter 7 Communication Issues and Internet Use, CIGR Handbook of Agricultural Engineering, 7, 435452.

BOSCH, 2006: "CAN Specification Version", Available at: http://www.can.bosch.com.
MURTHY,C.K., RAMAKRISHNA, R., 2009: Analysis of CAN Device to Determine the Performance of an Automotive Vehicle. European Journal of Scientific Research, 26, 34-47.

SUVINEN, A., SAARILAHTI, M., 2006: Measuring the mobility parameters of forwarders using GPS and CAN bus techniques. Journal of Terramechanics, 43, 237-252.

Ing. Jiř́ Čupera, Ph.D., doc. Ing. Pavel Sedlák, CSc., Ústav techniky a automobilové dopravy, Mendelova univerzita v Brně, Zemědělská 1, 61300 Brno, Česká republika, e-mail: xcupera@node.mendelu.cz, pavel. sedlak@mendelu.cz. 